\title{
Gallstone ileus: management options and results on a series of 40 patients
}

\author{
D. Martínez Ramos, J. M. Daroca José, J. Escrig Sos, G. Paiva Coronel, M. Alcalde Sánchez and \\ J. L. Salvador Sanchis
}

Service of Digestive and General Surgery. Hospital General de Castellón. Spain

\begin{abstract}
Introduction: controversy remains about the management of gallstone ileus. While some authors propose enterotomy, others defend the one-stage procedure (simultaneously fistula repair). The objective of the present study was to analyze management options and comparative study their results.

Material and methods: retrospective and descriptive study with revision of clinical stories of patients with the diagnosis of gallstone ileus between 1987 and 2008. All the following variables were recorded: dates of hospital admission, surgery and discharge, age, sex, pathological antecedents, preoperative or intraoperative diagnosis, treatment, location of the fistula and location of the obstruction. End-result variables were: postoperative complications, mortality, complications during the follow-up and biliary complications.

Results: a total of 40 patients were included of 46,648 admissions. Age, comorbidity, and intraoperative diagnosis were related with poorer short- and long-outcomes. The percentage of postoperative complications was similar for groups with and without fistula repair. Mortality was higher in the group with fistula repair (15 vs. 25\%). Biliary complications were more frequent in the group without fistula repair (11 vs. 0\%). Sex, location of the fistula and location of the obstruction did not be related with the prognosis.
\end{abstract}

Conclusion: one-stage procedure is related with higher mortality rate than enterotomy alone. Nevertheless, fistula repair reduces the number of biliary complications during the follow-up.

Key words: Gallstone ileus. Enterotomy. Biliary fistula.

Martínez Ramos D, Daroca José JM, Escrig Sos J, Paiva Coronel G, Alcalde Sánchez M, Salvador Sanchos JL. Gallstone ileus: management options and results on a series of $40 \mathrm{pa}-$ tients. Rev Esp Enferm Dig 2009; 101: 117-124.

Received: 27-11-08.

Accepted: 15-01-09.

Correspondence: David Martínez-Ramos. Servicio de Cirugía General y Digestiva. Hospital General de Castellón. Avda Benicàssim, s/n. 12004 Castellón, Spain.e-mail: davidmartinez@comcas.es

\section{INTRODUCTION}

Described first by Bartholin in 1654, gallstone ileus is defined as a mechanical obstruction of the gastrointestinal tract caused by the presence of a gallstone in its lumen. Up until now, the preferred treatment for these patients was enterotomy plus gallstone extraction (1-3). Since gallstone ileus is usually caused by a bilioenteric fistula, some authors have proposed that the fistula should be repaired in the same surgical act, accompanying enterotomy and cholecystectomy (one-stage procedure) (4). Nonetheless, this procedure is not exempt of complications and there is no definite agreement regarding the best therapeutical approach in such cases.

The objective of this study was to analyze the therapeutical options available for patients with a diagnosis of gallstone ileus, and to study the short- and long-term results of the most commonly performed procedures.

\section{MATERIAL AND METHODS}

This study consists of a retrospective review of hospital records for patients diagnosed with gallstone ileus and hospitalized in the Gastrointestinal and General Surgery Department in our hospital between November 1987 and October 2008. The total number of patients was 40 . From these records we obtained hospitalization dates, surgical procedure type and date, hospital discharge date, and last visit date. Variables initially studied were: age, gender, medical history, presurgical and surgical diagnosis with gallstone ileus, type of treatment applied, and anatomical localization of fistula and obstruction. To analyze the results, variables used included: immediate post-op complications, complications observed during follow-up - particularly biliary tract complications - and mortality rates.

The low incidence of this disease is the reason for the small number of patients seen in such a long period of 
time. Under these conditions the inferential analysis is not appropriate, hence only a descriptive analysis was made. Statistical calculations were performed with the program SPSS ${ }^{\oplus}$ Windows 15.0.

\section{RESULTS}

During the time period selected 46,648 patients were hospitalized in our department. Of these, 40 were diagnosed with gallstone ileus, which indicates an incidence of approximately $0.9 \%$ o $(1$ in 1,166$)$. The number of cases per year was relatively constant with an average of 2 hospitalizations per year. Table I shows the main features of the sample studied.

Median hospitalization for each patient was 14 days (range: 4-60). Post-surgical stay in hospital was approximately 9.5 days (range: $3-36$ ). The interquartilic range reveals the most representative hospitalization periods. For total hospital stay it was approximately 10-20 days, and for post-surgical stay it was approximately 7 to 16 days. There were atypical and extreme hospitalizarion periods, but as usual none of them are representative.

Prior to the surgery the following tests were performed: abdominal X-rays were for 40 patients, abdominal ultrasounds for 26 patients, and CT scans for 8 patients. These tests yielded no positive results in 3 patients, who underwent surgery with no established pre-op diagnosis. Rigler's triad (small-bowel dilation, ectopic gallstones, and aerobilia) was observed in 7 patients.

Table II shows the complications found in our series. The percentages shown in this table, and in the following one, were calculated with the total number of available cases, which did not always match the real totals of the series, mainly because of faulty data collection from hospital records. As shown in this table, patient older age (more than 80 years) was related to a poorer short-term prognosis, more post-op complications, and a greater mortality rate at hospitalization. Nonetheless, biliarytract and general complications seen during follow-up were less in number. These complications were observed more frequently in younger patients, probably because older patients, due to their age, died before such complications could develop. Comorbidity was associated with a worse short-term and long-term prognosis. However, the percentage of deaths during the post-op period was greater when there was no comorbidity present (11 against 25\%), but he number of cases, 3 patients in each group, was very low, making chance a possible reason for these apparently contradictory results. Finally, the percentage of immediate complications was greater when the diagnosis of gallstone ileus was made during the surgical procedure than when it was made prior to surgery. This difference, however, was not clinically relevant for long-term prognosis.

Table III shows the results of analyzing complications according to type of treatment performed. When entero-
Table I. Main features of the sample studied

\begin{tabular}{|c|c|c|c|}
\hline Variable & Median (range) & Frequency & $\begin{array}{l}\text { Percentage } \\
\text { (rounded) }\end{array}$ \\
\hline Age (years) & $78.3(43-92)$ & & \\
\hline $\begin{array}{l}\text { Hospital stay (days) } \\
\text { Total } \\
\text { Post-op } \\
\text { Diagnostic delay }\end{array}$ & $\begin{array}{l}16.2(2-60) \\
12.0(3-36) \\
4.4(0-51)\end{array}$ & & \\
\hline Follow up time (months) & $41.0(0-183)$ & & \\
\hline $\begin{array}{l}\text { Gender } \\
\text { Female } \\
\text { Male }\end{array}$ & & $\begin{array}{c}31 \\
9\end{array}$ & $\begin{array}{l}77.5 \\
22.5\end{array}$ \\
\hline $\begin{array}{l}\text { Comorbidity } \\
\text { Yes } \\
\text { No }\end{array}$ & & $\begin{array}{l}28 \\
12\end{array}$ & $\begin{array}{l}70 \\
30\end{array}$ \\
\hline $\begin{array}{l}\text { Pre-op diagnosis } \\
\text { Yes } \\
\text { No }\end{array}$ & & $\begin{array}{l}25 \\
15\end{array}$ & $\begin{array}{l}62.5 \\
37.5\end{array}$ \\
\hline $\begin{array}{l}\text { Imaging findings } \\
\text { Small-bowel distension } \\
\text { Pneumobilia } \\
\text { Intestinal calculi }\end{array}$ & & $\begin{array}{c}28 \\
23 \\
9\end{array}$ & $\begin{array}{c}70 \\
57.5 \\
22.5\end{array}$ \\
\hline $\begin{array}{c}\text { Number of imaging findings } \\
0 \\
1 \\
2 \\
3\end{array}$ & & $\begin{array}{c}3 \\
17 \\
13 \\
7\end{array}$ & $\begin{array}{r}7.5 \\
42.5 \\
32.5 \\
17.5\end{array}$ \\
\hline $\begin{array}{l}\text { Treatment } \\
\text { Enterotomy } \\
\text { Enterotomy + fistula repair } \\
\text { Intestinal resection } \\
\text { Conservative }\end{array}$ & & $\begin{array}{c}27 \text { (1 laparoscopic) } \\
4 \\
2 \\
5\end{array}$ & $\begin{array}{c}67.5 \\
10 \\
5 \\
12.5\end{array}$ \\
\hline $\begin{array}{l}\text { Location of fistula } \\
\text { Duodenum } \\
\text { Jejunum } \\
\text { lleum } \\
\text { Unknown }\end{array}$ & & $\begin{array}{c}21 \\
1 \\
1 \\
17\end{array}$ & $\begin{array}{c}52.5 \\
2.5 \\
2.5 \\
42.5\end{array}$ \\
\hline $\begin{array}{l}\text { Location of obstruction } \\
\text { Duodenum } \\
\text { Jejunum } \\
\text { lleum } \\
\text { Unknown }\end{array}$ & & $\begin{array}{l}1 \\
16 \\
13 \\
10\end{array}$ & $\begin{array}{c}2.5 \\
40 \\
32.5 \\
25\end{array}$ \\
\hline $\begin{array}{l}\text { Complications } \\
\text { Post-op }\end{array}$ & & & \\
\hline $\begin{array}{l}\text { Yes } \\
\text { No } \\
\text { Follow-up } \\
\text { Yes } \\
\text { No }\end{array}$ & & $\begin{array}{l}18 \\
22 \\
6 \\
34\end{array}$ & $\begin{array}{l}45 \\
55 \\
\\
15 \\
85\end{array}$ \\
\hline $\begin{array}{c}\text { Biliary } \\
\text { Yes } \\
\text { No }\end{array}$ & & $\begin{array}{c}3 \\
37\end{array}$ & $\begin{array}{c}7.5 \\
92.5\end{array}$ \\
\hline $\begin{array}{l}\text { Death during hospitalizatio } \\
\text { Yes } \\
\text { No }\end{array}$ & & $\begin{array}{c}6 \\
34\end{array}$ & $\begin{array}{l}15 \\
85\end{array}$ \\
\hline
\end{tabular}


Table II. Complications according to different factors

\begin{tabular}{|c|c|c|c|c|c|c|}
\hline \multirow[t]{2}{*}{ Complications } & \multicolumn{2}{|c|}{ Age } & \multicolumn{2}{|c|}{ Comorbidity } & \multicolumn{2}{|c|}{ Gallbladder ileus diagnosis } \\
\hline & $<80$ years & $\geq 80$ years & Yes & No & Pre-op & Intra-op \\
\hline Post-op complications & $7(39 \%)$ & $11(50 \%)$ & $14(50 \%)$ & $4(33 \%)$ & $10(40 \%)$ & $8(53 \%)$ \\
\hline Death during hospitalization & $1(6 \%)$ & $5(23 \%)$ & $3(11 \%)$ & $3(25 \%)$ & $3(12 \%)$ & $3(20 \%)$ \\
\hline Death during follow-up & $4(22 \%)$ & $2(9 \%)$ & $5(18 \%)$ & $1(8 \%)$ & $4(16 \%)$ & $2(13 \%)$ \\
\hline Billiary complications & $2(11 \%)$ & $1(4 \%)$ & $3(11 \%)$ & 0 & $2(8 \%)$ & $1(7 \%)$ \\
\hline
\end{tabular}

Table III. Complications according to treatment

\begin{tabular}{|c|c|c|c|c|c|}
\hline \multirow[t]{2}{*}{ Complications } & \multirow[b]{2}{*}{ Enterotomy } & \multicolumn{4}{|c|}{ Treatment } \\
\hline & & Enterotomy + fistula repair & Conservative & Intestinal resection & Total \\
\hline Post-op complications & $13(48 \%)$ & $2(50 \%)$ & $1(20 \%)$ & $2(100 \%)$ & 18 \\
\hline Death during hospitalization & $4(15 \%)$ & $1(25 \%)$ & 0 & $1(\%)$ & 6 \\
\hline Death during follow-up & $5(18 \%)$ & $1(25 \%)$ & 0 & 0 & 6 \\
\hline Billiary complications during follow-up & $3(11 \%)$ & 0 & 0 & 0 & 3 \\
\hline
\end{tabular}

tomy was performed alone, the percentage of post-op complications was similar to that in the group that underwent enterotomy plus fistula repair. However, the mortality rate was greater in the latter (25 against $15 \%$ ), while biliary tract complications were more frequent in the former. This table also shows that with conservative treatment only one patient in five $(20 \%)$ had immediate complications, and no complications were observed during their follow-up period. Finally, when intestinal resection was needed, the percentage of complications was $100 \%$, leading to death in 1 every 2 patients.

Other variables such as gender, or fistula or obstruction anatomical localization showed no clinical relevance whatsoever in the incidence of complications, both in the immediate post-op period and during follow-up.

\section{DISCUSSION}

Gallstone ileus is an infrequent complication of gallstone disease; it is the cause of 1 to $3 \%$ of mechanical obstructions in the small bowel (5-7). This low incidence, which is also observed in our analysis, results in very few prospective studies, and in reduced sample sizes in those available. Because of this, a retrospective and descriptive study like the one reported, despite obvious limitations, is of great interest, as few publications have achieved the number of patients included herein. Of course, the ongoing controversy about the best therapeutical options concerning gallstone ileus completely justifies these studies.

Even though there is universal agreement on surgery as first-option treatment for these patients, there is still reasonable disagreement about the need of fistula repair. While some authors (7-9) recommend one-stage procedures as the treatment of choice, with enterotomy alone being limited to unstable patients, most authors $(5,6,10$ 13) advocate for enterotomy alone as first choice of treat- ment, followed by a second surgery only for symptomatic patients or patients developing complications during follow-up. This way the first surgery is technically simpler and faster. In the greatest literature review, made by Reissner and Cohen (14), with more than 1,000 cases collected, results showed that the mortality rate for the onestage procedure was $16.9 \%$, compared to $11.7 \%$ for enterotomy alone. However, $10 \%$ of patients subjected to enterotomy alone needed reintervention because of biliary-tract symptoms detected during follow-up. Our data match Reissner and Cohen's work, showing that the group of patients with fistula repair presented a greater mortality than the group with enterotomy alone (25 against $15 \%$ ). Accordingly, the percentage of biliary tract complications for the enterotomy only group was $11 \%$, compared to $0 \%$ in the group that also had fistula repair.

Therefore, taking into account both the bibliographical review and our own experience, fistula repair cannot be recommended during the same surgical act as the treatment of choice for gallstone ileus in all patients. This technique is clearly associated with greater mortality. The therapeutical decision should balance the risks and benefits of each type of procedure, considering that most patients were older than 78 years, $70 \%$ had comorbidities, most had a delayed diagnosis (approximately 4 days in our series), and surgery was done under emergency conditions. In our opinion, the one-stage procedure should be performed in patients with greater life expectancy, less comorbidity, and no technical impairments.

On the other hand, 5 patients in our series did not undergo surgery, but were treated conservatively with nasogastric decompression, intravenous fluids, pain killers, etc. Eventually, all these patients spontaneously eliminated their gallstones via the rectum with a fairly satisfactory follow-up. Some authors have reported spontaneous elimination of gallstones in up to $5-7 \%$ of patients $(10,15,16)$, a little lower than the percentage found in our series. There are 
2 possible explanations for the positive results observed with conservative treatment in selected patients. The first one suggests that the occlusion was not complete, making spontaneous resolution more plausible. The second one, related to the first one, refers to a characteristic phenomenom called tumbling, where a gallstone continually migrates along the gastrointestinal tract producing symptoms whenever it obstructs a part of the lumen, which recede when the obstacle is overcome and recur when another tract segment is blocked, over and over again $(17,18)$. Nevertheless we do not recommend conservative treatment in these patients, despite the positive results observed in the literature, because in our series the non-surgical treatment was performed exceptionally.

Finally, it has been demonstrated that a laparoscopic approach, recently used in one of our patients, results in fewer complications in high-risk patients (19). This technique requires a mini-laparotomy in order to extract the intestinal segment with the impacted gallstone. However, the personal experience of a surgeon with this type of technique may produce biased results. We agree with other authors $(19,20)$ that this surgical procedure may be considered a first-choice option, despite obvious limitations. Since the general experience with this approach is still limited, new studies should be performed in order to define the specific indications for laparoscopic access in patients with gallstone ileus. It should be stated that there still are no publications comparing the results of the laparoscopic approach versus the one-stage procedure and two-stage surgery. Other therapeutical options such as lithotripsy or Kopel's maneuvers (forcing the gallstone through Bauhin's valve) were not performed in any of our patients, therefore we cannot discuss them in this text.

To summarize, according to a literature review and our own experience, the one-stage procedure (enterotomy, fistula repair, and cholecystectomy) is strongly associated with greater mortality. On the other hand, fistula repair and cholecystectomy in the same surgical act reduce the need for reintervention and the incidence of complications related to fistular persistence, including recurrent ileus, cholecystitis, or cholangitis. Some individual factors such as age and clinical stability should be taken into consideration when choosing the most appropriate treatment for each patient.

\section{REFERENCES}

1. Masannat Y, Masannat Y, Shatnawei A. Gallstone ileus: a review. Mount Sinai J Med 2006; 73: 1132-4.

2. Echenique Elizondo M, Amondaraín Arratíbel JA, Lirón de Robles Sanz C. Íleo biliar. Rev Esp Enferm Dig 2007; 99: 672-80.

3. Pozo Moreno R, Rojas Feria M, Pallares Manrique H, Ramos Lora M, Domínguez Macías A. Íleo biliar en paciente de edad avanzada. Rev Esp Enferm Dig 2008; 100: 432-3.

4. Sevilla Molina MP, Sánchez Blanco JM, Escribano Negueruela L, Gómez Rubio D, Recio Moyano G, Campoy Martínez P. Biliary ileus: enterolithotomy only or radical surgery? Rev Esp Enferm Dig 1992; 81: 407-10.

5. Ayantunde AA, Agrawal A. Gallstone ileus: diagnosis and management. World J Surg 2007; 31: 1292-7.

6. Casals Garrigo R, Mias Carcaball MC, de la Fuente Juárez MC, et al. Valoración del paciente con íleo biliar. Tratamiento y seguimiento. Cir Esp 2000; 67: 264-7.

7. Khan RN, Tayeb M. Gallstone ileus: retrospective review of a single centre's experience using two surgical procedures. Singapore Med J 2008; 49: 624-6.

8. Clavien PA, Richon J, Burgan S, Rohner A. Gallstone ileus. Br J Surg 1990; 77: 737-42.

9. Pavlidis TE, Atmatzidis KS, Papaziogas BT, Papaziogas TB. Management of gallstone ileus. J Hepatobiliary Pancreat Surg 2003; 10: 299-302.

10. Rodriguez Hermosa JI, Codina Cazador A, Gironès Vilà J, Roig M, Figa F, Acero D. Íleo biliar: resultados del análisis de una serie de 40 casos. Gastroenterol Hepatol 2001; 24: 489-94.

11. Doko M, Zovak M, Kopljar M, Glavan E, Ljubicic N, Hochstädter H. Comparison of surgical treatments of gallstone ileus: preliminary report. World J Surg 2003; 27: 400-4.

12. Rodríguez-Sanjuán JC, Casado F, Fernández MJ, Morales DJ, Naranjo A. Cholecystectomy and fistula closure versus enterolithotomy alone in gallstone ileus. Br J Surg 1997; 84: 634-7.

13. Tan YM, Wong WK, Ooi LLPJ. A comparison of two surgical strategies for the emergency treatment of gallstone ileus. Singapore Med J 2004; 45: 69-72.

14. Reisner RM, Cohen JR. Gallstone ileus: a review of 1001 reported cases. Am Surg 1994; 60: 441-6.

15. Ihara E, Ochiai T, Yamamoto K, Kabemura T, Harada N. A case of gallstone ileus with spontaneous evacuation. Am J Gastroenterol 2002; 97: 1259-60

16. Noriega Maldonado O, Bernal Mendoza LM, Rivera Nava JC, Guevara-Torres L. Íleo biliar. Cir Ciruj 2005; 73: 443-8.

17. Salazar Lozano C, Rocha Guevara E, Vargas Gismondi A, de la Fuente Lira M, Ernesto de Obaldía-Zeledón R, Cordero Vargas C. Íleo biliar y fístula colecistoduodenal. Cir Ciruj 2006; 74: 199-203.

18. Keogh C, Brown JA, Torreggiani WC, MacFarlane J, Halperin L. Recurrent gallstone ileus: case report. Can Assoc Radiol J 2003; 54: 90-2.

19. Moberg AC, Montgomery A. Laparoscopically assisted or open enterolithotomy for gallstone ileus. Br J Surg 2007; 94: 53-7.

20. Ferraina P, Gancedo MC, Elli F, Nallar M, Ferraro A, Sarotto L, et al. Video-Assisted Laparoscopic enterolithotomy: new technique in the surgical management of gallstone ileus. Surg Laparosc Endosc Percutan Tech 2003; 13: 83-7. 